УДК 801.61

DOI: $10.21779 / 2542-0313-2021-36-3-82-94$

\title{
Х.М. Аминова
}

\section{Передача ритма стиха В. Маяковского в переводах Ю. Хаппалаева}

Дагестанский государственный университет; Россия, 367000, г. Махачкала, ул. М. Гаджиева, 43a; hazinat_63@mail.ru

В статье исследуются ритмико-интонационные особенности перевода стихотворений В. Маяковского «Левый марш» и «Товарищу Нетте - пароходу и человеку» на лакский язык, выполненные Ю. Хаппалаевым. Учитывая важность максимального сохранения ритма, автор особое внимание уделяет разбивке строк, передаче размера, количества стоп в строке, видов интонации, синтаксиса, рифменной системы. В статье дается сравнительно-сопоставительный анализ оригинала и его лакского варианта исходя из методологической установки: все структурные элементы стиха, включая метр, число слогов, рифму и т. д. должны переводиться в той мере, в какой это позволяют делать язык перевода, поэтические традиции и новации литературы. Изучение перевода новаторского стиха В.В. Маяковского на лакский язык позволяет проследить возможности передачи средствами силлабики тонического, акцентного стиха русского поэта. В результате проведенного исследования можно утверждать, что и на лакском языке В. Маяковский звучит вполне адекватно. Для Ю. Хаппалаева перевод - это не только возможность проявить свой талант, но и один из способов его самосовершенствования.

Ключевые слова: поэтический перевод, стих, ритм, интонация, тонический стих, силлабика, В. Маяковский.

Поэтический перевод представляет собой сложную систему прежде всего потому, что в нем сращены содержание и форма, «нигде больше эстетическая информация не представлена такой концентрацией средств, как в поэзии» [1, с. 318], и «чтобы не быть мертвым, а живым, перевод должен воспроизводить форму оригинала, ибо в этой форме живет, разлито в ней и неотделимо от нее содержание» [10, с. 98]. Как справедливо отмечают современные переводоведы, «проблем перевода поэзии несколько: поэзия часто имеет несколько уровней смысла, и часто за очевидным верхним слоем, который с первого взгляда может показаться прозаическим или бесхитростным, в процессе дискуссии открывается все более богатыми нижними слоями, нередко даже не имеющими единой общей смысловой интерпретации» [4, с. 78]. Как правило, невозможно точно воспроизвести все формальные особенности подлинника, переводчику необходимо по возможности «сохранять лишь формы, несущие семантические функции» [11, с. 86]. Свобода творчества переводчика поэзии, по мнению многих исследователей, заключается в осознании необходимости передачи «наиболее существенных сторон подлинника» [10, с. 131].

Передача ритмических особенностей оригинала, поиск ритмических соответствий являются одними из сложных вопросов перевода. В каждом языке своя верификационная культура, и она не может быть механически перенесена на другой язык. Различия в поэтической культуре объясняют существование также и полярных подходов к решению проблемы ритма в поэтическом переводе. Часть теоретиков и практиков пе- 
ревода трактуют ритм как формальную характеристику текста, не требующую обязательной передачи в переводе, другие - осознают смыслообразующую роль ритма в поэтическом тексте как музыкально-семантического единства и считают невозможным передать ритм оригинала в переводе. К примеру, Г. Гачечиладзе считает, что «при переводе легче передать ритм поэтического подлинника, чем его метр, который в силу различия языков гораздо труднее, а зачастую невозможно воспроизвести на другом языке... И поэтому при поэтическом переводе необходимо воссоздавать отношение между ритмом и интонацией, а не размер оригинала» [6, с. 219].

Подобной точки зрения придерживается и И. Левый, считая, что звуковые качества переводимого текста «правильнее будет переводить не «размером подлинника», а «ритмом подлинника» [11, с. 65]. Еще более радикально выразился Г. Орагвелидзе: «Переводчик должен следовать не мелодии самого слова, а ритмической интонации самого содержания, должен соблюдать не формальный ритмический рисунок (одинаковый подсчет слогов и т. д.), а внутреннее ритмическое устремление поэта» [14, с. 9]. Полагаясь только на ассоциативный перевод, при котором игнорируется конкретная поэтика оригинала, переводчики рискуют упустить особенность оригинала и превратить «чужой текст» в собственные эстетические ценности. Перевод, ориентированный на передачу лишь содержания, оказался бы в лучшем случае «вольным переводом».

Таким образом, исследователи единодушны в том, что легко соотносимые в языке оригинала ритм и интонация становятся проблемой при передаче их на другие языки. Особенно актуальным становится поиск ритмических эквивалентов при реализации перевода в условиях неродственных языков. С подобными высказываниями трудно согласиться.

По словам Идиатуллиной Л.Т. «произведения В. Маяковского переведены на 42 иностранных языка и 56 языков народов СССР. На иностранные языки переводы произведений Маяковского были осуществлены несколько ранее, чем на языки народов СССР. Первые переводы Маяковского на европейские языки были сделаны еще в 1921-1922 гг. В большинстве случаев переводы отдельных стихотворений и статьи о Маяковском публиковались в различных периодических изданиях, и лишь гораздо позже некоторые из них вошли в антологии русской поэзии и драмы» [8, с. 62]. К сожалению, не удалось избежать и неоправданной критики этих переводов, гиперболизации негативного, односторонних оценок, отрицания всего, что напоминало о прежней эпохе. В постперестроечный период творчество Маяковского в числе первых попало под огонь критики, и переводы его произведений более не появлялись, прекратилось и их изучение. В то время как именно переводы произведений поэта-новатора, каким являлся В. Маяковский, открывают новые перспективы развития теории и практики как перевода, так и собственно национальной поэзии.

Рассмотрим переводы стихотворений В. Маяковского, осуществленные Ю. Хаппалаевым на лакском языке, с точки зрения воссоздания ритмико-интонационной организации стихотворений русского поэта. Ю. Хаппалаев - профессиональный переводчик, чья переводческая деятельность высоко оценивалась дагестанскими исследователями-переводоведами, в частности Э.Ю. Кассиевым и А.А. Абдуллаевым [2; 10]. Он перевел стихотворения классиков русской и советской литературы Пушкина, Лермонтова, Есенина, Исаковского, украинских поэтов Т. Шевченко, И. Франко, Л. Украинки. Нельзя не отметить несомненные заслуги Ю. Хаппалаева в переводе на родной язык таких больших по объему произведений, как армянский эпос «Давид Сасунский», грузинский - «Витязь в тигровой шкуре» Ш. Руставели, индийский - «Махабхарата» и т. д., а также трудные для перевода стихотворения В. Маяковского «Левый марш», 
«Стихи о советском паспорте», «Товарищу Нетте - пароходу и человеку», отрывок из поэмы «В.И. Ленин» [13].

Говоря о переводах, осуществленных Ю. Хаппалаевым, Э. Кассиев дает лаконичную характеристику: «Ю. Хаппалаев - хороший переводчик» [10, с. 105]. Нельзя не согласиться со справедливой оценкой: «Ему (Ю. Хаппалаеву. $-X$. $A$.) удалось органически воплотить синтез реалистического и романтического начал в переводческом деле, обозначить приоритетную тенденцию современного перевода поэзии с русского языка на лакский, создать также переводные произведения, которые своими художественно-эстетическими характеристиками схожи с оригинальными стихотворениями на лакском языке» [3, с. 136]. Созданная Ю. Хаппалаевым лакская переводная поэзия, еще не подвергшаяся глубокому научному анализу, заслуживает серьезного исследования.

Бесспорно, Ю. Хаппалаев осознавал содержательность формы стиха В. Маяковского, ритм которого основан на особенностях просодии русского языка. Переводчик стремился найти пути, чтобы приблизиться к ритму оригинала средствами национальной системы стихосложения. В условиях неродственных языков переводить, сохраняя ритм, размер оригинала, - нелегкая задача. В частности, для лакского поэта, привыкшего к традиционной силлабике, - это задача не из простых. Однако переводы Ю. Хаппалаева показали, что и на лакском языке стих В. Маяковского может звучать как акцентный стих, что его можно переводить не равносложным силлабическим стихом, а именно стихом, в котором присутствуют тонические акценты.

Как отмечают исследователи поэзии В. Маяковского, поэт не признавал традиционных размеров. Полиритмические композиции его стихов объединяются стилем и единой синтаксической интонацией, которая задается графической подачей стиха. Знаменитая «лесенка» стала визитной карточкой поэта и помогала ему скандировать стихи с более правильной интонацией, так как запятых было недостаточно. В. Маяковский также не признавал и традиционную мелодийность поэтической речи. В отличие от своих предшественников он стремился приблизить поэтическую речь к говорной, сделать стих режущим слух. Своей поэтической грубостью и экспрессивностью В. Маяковский создал образ лирического героя-поэта, вождя уличных толп, певца городских низов. «Форма поэзии Маяковского органично слита с ее содержанием. Выделение им слов в отдельные строки - это не формальный, а смысловой момент. Но (в переводе. $X$. A.) слова эти сохранят свою силу только тогда, когда они строфически будут совпадать с оригиналом. Для такого совпадения надо найти адекватный оригиналу ритмический строй перевода» [16].

Переводы стихотворений В. Маяковского, сделанные Ю. Хаппалаевым, демонстрируют способы передачи на лакском языке основных сторон ритмико-интонационных особенностей поэтики русского поэта. Стихотворение «Левый марш» сразу же завоевало популярность и было переведено на многие языки мира. Оно оказалось удивительно созвучно времени и своей тематикой, и своей идеей, и своей интонацией, и тональностью. «Революционный бунт, накал страстей, призыв, стремление к новому, т. е. все то, чем пропитана атмосфера того времени, отражены в этом стихотворении, поэтому оно оказалось близко поэтам-переводчикам, которые испытывали те же чувства, что и русский поэт» $[9$, с. 511].

Плодотворными оказались идеи единения поэта с революционными матросами, его разговор с ними о накаленной атмосфере эпохи, о необходимости защищать молодую Советскую власть от враждебного окружения. С самого начала в стихотворении «Левый марш» задан высокий темп, передающий напряженность и ответственность исторического момента, что характерно для поэзии В. Маяковского: 
Разворачивайтесь в марше!

Словесной не место кляузе.

Тише, ораторы!

Ваше

слово, товарищ маузер.

Довольно жить законом, данным Адамом и Евой.

Клячу историю загоним.

Левой!

Левой!

Левой!

Марширай сукку хьи гужну! В марше двигайтесь сильнее!

Ва бакъар лахъунтту бай к 1антту! Это не место для пересудов!

Лагьхьи зугу, оратортал! Тише, ораторьи!

Махъ тти Слово

вихьри, у тебя,

гьалмахчу маузер. товарищ маузер.

Адам Х1авалул закон Адама Хавы закон

кьаритан ч1унссар оставить пора

Тарихрал ябу бивк1уссар! Истории кляча подохла!

К1иямур! Левой!

К1иямур! Левой!

К1иямур! Левой! [13].

Стихотворение «Левый марш» как яркий образец агитационной поэзии построено в форме разговора, беседы, хотя сам автор предупреждает в первых же строках «Словесной не место кляузе». В. Маяковский использовал слово кляуза в значении «пустословие». В лакском языке нет слова кляуза, и Ю. Хаппалаев перевел это выражение в прямом смысле «Ва бакъар лахъунтту бай к1антту» (букв.: это не место для пересудов). «Тише, ораторы! Ваше слово, товарищ маузер». Поэт подчеркивает, что бессмысленными разговорами и пересудами врага не победишь.

Бескомпромиссность политической борьбы В. Маяковский подчеркивает категорическими выпадами, порой эпатируя своих слушателей и оппонентов.

Эй, синеблузые!

Рейте!

За океаны!

Или

у броненосцев на рейде

ступлены острые кили?!

Пусть, оскалясь короной, вздымает британский лев

вой.

Коммуне не быть

покоренной.

Левой! 
Левой!

Левой!

Гьей, няк1 гьухьри лавхмий! Эй, одетые в синие рубахи!

Бигьлагьи! Пльвите!

Океаннайх! По океану!

Юхсса къуркъа хьурив бац1аврил Или отупели от остановки

Байл хъуртти жамирдал?! Острые кльки кораблей?!

Бити гъургъу т1инма ингилис аслан,

Оставь, пусть продолжсает рычать английский лев,

Коммуна мют1и къахьунт1иссар. Коммуна не покорится.

К1иямур! Левой!

К1иямур! Левой!

К1иямур! Левой!

Здесь время спрессовано, все чувства обострены, некогда рассуждать, пришло время действовать. В. Маяковский, используя всю силу образного слова, воздействовал в первую очередь на слушателя, а только потом на читателя. Необходимо быть понятым широкими слоями масс. Отсюда простота, выразительность и краткость его стиха. Главная идея стихотворения - вдохновить идущих в бой матросов, вселить в них уверенность в правильности борьбы. Сражение будет трудным, молодая Советская власть в опасности, но ее защитники должны объединиться, выстоять и победить.

Там

за горами горя

солнечный край непочатый.

За голод

за мора море

шаг миллионный печатай!

Пусть бандой окружат

нанятой,

стальной изливаются леевой, -

России не быть под Антантой.

Левой!

Левой!

Левой!

Дардирдал зунттал тих Там за горами горя

Баргъ бивт улча хъунмассар. Солнечная сторона большая.

Ккашихлу, ц1аллил хьхьирихлу За голод, за море осnь

Мильон шаттирдал сурат рищара! Миллион иагов рисунок отпечатай!

Бити лагма ругьлай къачагъ-бандарду, Пусть окружают воры-банды,

Бити т1 инма цинма: «Чаннан-асланна», Пусть говорят себе: "Я стальной лев»,

Антантанал хяппухь Аьрасат къабикlантlиссар! Россия не будет в лапах Aнmaнmbl!

К1иямур! Левой!

К1иямур! Левой!

К1иямур! Левой! 
Следующая строфа - это уже обобщение, призыв к объединению пролетариата всего мира. Форма стихотворения «Левый марш» соответствует поэтическому темпераменту и стилю поэта. Рефрен «Левой! Левой! Левой!» подчеркивает четкость шага матросов и звучит как команда к бою, наполняет оптимизмом. Шагают не просто солдаты, а сознательные революционеры, уверенные в своей правде: те, которые идут по верному пути и могут победить, даже любого самого сильного врага. Им нет дороги назад:

Глаз ли померкнет орлий?

В старое ль станем пялиться?

Крепи

у мира на горле

пролетариата пальцы!

Грудью вперед бравой!

Флагами небо оклеивай!

Кто там шагает правой?

Левой!

Левой!

Левой!

Барзуллив я мурч1и шайсса? Ослепнет ли глаз орла?

Духмурдив тти лаххант1исса?! В старое ли оденемся?!

Цакь ба дунияллул хъат1лий пролетарнал к1исри! Укрепи на горле пролетариаmа пальцыь!

Няк1 ссав дуща ттугъай! Синее небо покрой флагами!

Чувнал хъазам хьхьич1унмай! Грудь героя вперед!

Цу ур микку урч1ахмур ласлай? Кто там шагает правой?

К1иямур! Левой!

К1иямур! Левой!

К1иямур! Левой!

Стихотворение «Левый марш» В. Маяковского признано одним из бесспорных шедевров его поэзии [9, с. 511], оно великолепно с точки зрения и формы и содержания. Поэт точно воспроизводит ритм марширующих революционно настроенных матросов и свои слова напутствия перед решительным боем, вселяя в них уверенность, призывая к решительным действиям. Интонация стихотворения построена по принципу ораторской речи, в которой много вопросительных и восклицательных конструкций: «Разворачивайтесь в марше!» (Марширай сукку хьи гужну!), «У броненосцев на рейде ступлены острые клыки?!» (Юхсса къуркъа хьурив баиІаврил Байл хъуртти жамирдал?!), «России не быть под Антантой!» (Антантанал хяппухь Аьрасат къабикlaнтlucсар!), «Глаз ли померкнет орлий?» (Барзуллив я мурчlи шайсса?), «В старое ль станем пялиться?» (Духмурдив тти лаххант1исса?!), «Грудью вперед бравой!» (Чувнал хъазам хьхьичlунмай!), «Кто там шагает правой?» (Цу ур микку yрчlaхмур ласлай?), «Пусть, оскалясь короной, вздымает британский лев вой» (Бити гъургъу тІинма ингилис аслан), «Грудью вперед бравой!» (Чувнал хъазам хьхьичlунмай!), «Флагами небо оклеивай» (Няк1 ссав дущуа ттугъай), «Эй, синеблузые!» (Гьей, някl гъухъри лавхмий!). 
Перевод стихотворения не только ритмически совпадает, но и повторяет деление оригинала на подстрочия. Проследим, совпадает ли количество слогов.

Глаз ли померкнет орлий? (7)

В старое ль станем пялиться? (7)

Крепи (2)

у мира на горле (5)

пролетариата пальцы! (8)

Грудью вперед бравой! (6)

Флагами небо оклеивай! (9)

Кто там шагает правой? (7)

Левой! (2)

Левой! (2)

Левой! (2)

Барзуллив я мурч1и шайсса? (8) Ослепнет ли глаз орла?

Духмурдив тти лаххант1исса?! (8) В старое ли оденемся?!

Ц1акь ба Укрепи (2)

дунияллул хъат1лий (6) на горле мира

пролетарнал к1исри! (6) пролетариата пальцьь!

Няк1 ссав дуща ттугъай! (6) Синее небо покрой флагами!

Чувнал хъазам хьхьич1унмай! (7) Грудь героя вперед!

Цу ур микку урч1ахмур ласлай? (9) Кто там шагает правой?

К1иямур! Левой! (3)

К1иямур! Левой! (3)

К1иямур! Левой! (3)

Русский и лакский стих относятся к разным верификационным системам. Как известно, русское стихосложение силлабо-тоническое, лакское - силлабическое. Однако можно найти и точки сближения, ведь и русское стихосложение вплоть до XVIII века было силлабическим, а в современной лакской поэзии стали развиваться альтернативные традиционной силлабике системы, например верлибр (свободный стих), что демонстрируют переводы Ю. Хаппалаева.

Ритм в стихах В. Маяковского основан в первую очередь на особенностях русского языка, поэтому размер стиха «Левый марш», определенный как дольник, невозможно механически перевести на другой, в том числе и лакский язык. Ю. Хаппалаев один из экспериментаторов в лакской поэзии, прочувствовал маршевую интонацию стихотворения, интонационные волны, положение слов в строке и добился аналогии с оригиналом, несмотря на то что синтаксические и фонетические возможности лакского языка не всегда это позволяют. Ю. Хаппалаев естественно использовал для его перевода средства лакского стихосложения. Мелодика «Левого марша» Ю. Хаппалаева во многом отличается от мелодики традиционного силлабического стиха - это свободный стих, построенный на гармонии, возникающей в результате различных видов повтора и интонационных сдвигов. Следует также уточнить, что в лакском языке синтаксис достаточно регламентирован по сравнению с русским языком, и слова находятся в определенном положении в строке, поэтому явление инверсии ему не свойственно. Однако для Ю. Хаппалаева, который довольно часто использует в своем творчестве инверсию, не составило труда воспроизвести строку В. Маяковского. 
В плане рифменного созвучия стихотворение «Левый марш», на наш взгляд, остается недостаточно эквивалентно переданным. Объективной причиной является то, что лакская поэзия традиционно не имеет рифмы. Рифменные находки В. Маяковского пялиться - пальиьы, орлий - горле, браво - правой, непочатый - печатай, рейте - рейде; левой - лев вой невозможно передать в лакском варианте. И хотя переводчик находит способы скрепления свободного стиха фонетическими видами повтора в рифме тугъай - ласлай, в анафоре Бити - Бити, стихотворение в целом остается нерифмованным. Возможно, это потому, что в своей оригинальной поэзии Ю. Хаппалаев не использует рифму как инструмент ритмической и строфической организации стиха. В любом языке могут быть найдены аналоги рифмам В. Маяковского. Речь, конечно же, идет не о механическом переносе в перевод звуков оригинала, а о сохранении рифменной системы оригинала, типов рифмовки и самой рифмы, так как принципы рифмования, несмотря на различающиеся звуковые системы, в разных языках совпадают.

Как видно, в переводе на лакский язык ритма и звукописи стихотворения «Левый марш» мы с трудом найдем прямые соответствия с оригиналом. Для лакского поэта, привыкшего к традиционной силлабике, передача ритма тонических стихов В. Маяковского - задача не из простых. Однако перевод стихотворения «Левый марш» дает возможность читателю почувствовать иную, нетрадиционную для родной литературы стиховую культуру.

В переводах В. Маяковского Ю. Хаппалаеву пришлось осваивать приемы паузировки текста, разбивки его на отрезки и создания так называемой «лесенки» средствами лакского языка. К примеру, фрагмент из поэмы «Владимир Ильич Ленин»:

Мозг класса,

дело класса,

сила класса, слава класса -

вот что такое партия.

Партия и Ленин -

близнецы-братья, -

кто более

матери-истории ценен?

Мы говорим - Ленин, подразумеваем -

партия,

мы говорим -

партия, подразумеваем -

Ленин.

Классрал ня, Класса мозг,

классрал иш, класса дело,

классрал гуж, класса сила,

классрал ц1а - класса имя -

вана вари партия. вот это партия.

Партия ва Ленин - к1инничалт-уссурвалли. Партия и Ленин - близнецьь-братья. Цума ур Кто имеет

Лапва кьимат бусса Высокий авторитет 
Нину-тарихран? Для матери-истории?

Жува т1ий буру - Ленин, Mb говорим Ленин,

Дак1ний дургьуну - партия. В душе держим - партия.

Жува т1ий буру партия, $M$ в говорим партия,

Дак1ний увгьуну Ленин. - В дуще держим - Ленин.

Перевод демонстрирует, что и на лакском языке стих В. Маяковского может звучать как акцентный стих, что его можно переводить не равносложным стихом и не верлибром, а именно тоническим стихом. Стремясь адекватно передать интонацию оригинала, Ю. Хаппалаев и в своем переводе сохранил по четыре удара в каждом стихе. Что касается рифмы, переводчик заменил ее начальной рифмой - анафорой, это, в свою очередь, придает определенную ритмичность стиху:

Классрал ня, Класса мозг, классрал иш, класса дело, классрал гуж, класса сила, классрал ц1а, класса имя вана вари партия. вот это партия.

Соответствующую картину мы наблюдаем и в переводе стихотворения «Товарищу Нетте - пароходу и человеку». Для создания ритма в стихе В. Маяковского нет необходимости строго соблюдать размер. Для поэта более важно варьирование длины стихотворной строки, подчеркивание паузы.

Подойди сюда!

Тебе не мелко?

От Батума, чай, котлами покипел...

Помнишь, Нетте, в бытность человеком

ты пивал чаи

Медлил ты. со мною в дипкупе?

Захрапывали сони.

Глаз

кося напролет в печати сургуча, болтал о Ромке Якобсоне и смешно потел, стихи уча.

Засыпал к утру.

$$
\text { Курок }
$$

аж палец свёл...

Суньтеся -

кому охота!

Думал ли,

что через год всего

встречусь я с тобою - 
За кормой лунища.

$$
\text { с пароходом. }
$$

Ну и здорово!

Залегла,

просторы надвое порвав.

Будто навек

$$
\text { за собой }
$$

из битвы коридоровой

тянешь след героя,

светел и кровав...

Стихотворение «Товарищу Нетте - пароходу и человеку» написано свободным стихом. Количество слогов в строке колеблется от 1 (Глаз...) до 8 (болтал о Якобсоне). Это колебание количества стоп в строке создает особый ритм стихотворения. Этот фрагмент звучит на лакском языке:

Ачу шиккунай Подойди-ка сюда

Батумраваягу най акъарав чара... Идешь аж от Батума говоришь...

Дак1нийрив вин, Нетте, Помнишь, Нетте,

пароходрайн к1ура аяннин, инсансса ч1умал, не превратился пока в пароход, будучи человеком

Ина ттущал чай х1ач1айссия дипкупелуву? Tы пивал со мной чай в дипкупе?

Шанашалт ххюнхху т1ий шанай бик 1айва, Сони, храпя, спали,

Инама я лакьин анавар къауккайвав. А ты глаз сомкнуть не спешил.

Оьрус хъамуй бивщу мугьрурдах На печать из русского сургуча

Ца ягу битлай, одним глазом глядя,

Чани хьун мазурдил аьлимчу Якобсоннуя До утра об ученом языковеде Якобсоне

Буслан ик1айвав. Рассказывал.

Шеърирду лахьлайгу гьухъа итайвав. Запоминая стихи, ты потел.

Чаннахь я лакьирчангу, к1иссамур кьярт1лий... К утру хоть засыпал, палец же на курке...

Нигьакъаусайма - гъан хьувча ччима! Кто не боится - подходи желающий!

Вин таний дак1нийн багьайвавкьай Мог ли ты тогда подумать,

Дахьра ца шинава, на вищал ц1униц1а, Что только через год я снова с тобой,

Пароходращал хьуна акьинссассар т1ий?! С пароходом, встречусь?!

Хьхьирил майдан к1иххябувккун, вил махъ Просторы моря рассекая, сзади

Хъунмасса барз бур экьи лавгун, Большая луна распустилась

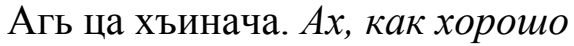

Зурул цила хъирив к1унк1у дурсса хханссар, Кажется, луна тянет за собой

Талатавриву нартнал кьариртсса Оставленный нартом в бою

Оьтту-ххялларисса сиппат. Кроваво-скалистый образ.

В этом переводе Ю. Хаппалаев не соблюдает ступенчатое деление строк, свойственное В. Маяковскому, отсюда и несовпадение длины строк и соответственно количества слогов в строке. Можно предположить, что текст Ю. Хаппалаева был графически изменен при издании (уменьшили объем стихотворения). Однако отсутствие «лесенки» обедняет перевод, так как расположение слов или группы слов на разных уровнях делает их значение более емким, самодостаточным. Ритм стихотворения, написан- 
ного «лесенкой», отличается: больше пауз, соответственно другая интонация, при чтении другое дыхание. Переводчик также не учел, что стихотворение В. Маяковского написано с использованием рифмы. Лакский вариант стихотворения «Товарищу Нетте - пароходу и человеку» - безрифменный свободный стих. Мы должны признать, что этот перевод Ю. Хаппалаева с точки зрения ритма, интонации, рифмы не совсем удачен. Перевод стихотворений В. Маяковского, в которых учитывается их ритмическая структура, - это довольно сложный процесс. Конфликт возникает там, где средствами родного языка переводчику необходимо передать не свойственную его поэзии ритмическую структуру.

Рассмотренные переводы В. Маяковского, осуществленные Ю. Хаппалаевым, определяются теми трудностями, с которыми сталкивается переводчик при работе над переводом произведения иной стиховой системы, а также выбором способов их преодоления. При переводе стихов В. Маяковского перед переводчиком встает множество задач, среди которых главная - сохранение эмоционального воздействия, бережное отношение к ритму стихотворения, строфике, рифме, иначе перевод теряет связь с текстом оригинала $[15$, с. 278]. В результате исследования можно заключить, что перевод стихотворения В. Маяковского «Левый марш» максимально приближен к оригиналу. У Ю. Хаппалаева получилось создать целостное с точки зрения содержания и формы произведение русского поэта на лакском языке.

Для достижения поставленной цели переводчику дозволено производить незначительные модификации с исходным материалом, что продемонстрировано в переводе стихотворения «Товарищу Нетте - пароходу и человеку». При передаче ритма стиха В. Маяковского переводчик позволяет неточности в переводе, так как главное - coхранять количество акцентов в строке. Ю. Хаппалаев перевел стихотворение свободным стихом, стараясь сохранить количество слогов в строке, но это не всегда получалось, разбивка строк на слова, группы слов, т. е. «лесенка» не всегда соблюдается. Также не соблюдается тип рифмовки, вследствие чего перевод звучит менее экспрессивно и неэмоционально. Несмотря на то что Эстетическое воздействие сохранено, в этом переводе единства формы и содержания, на наш взгляд, не получилось.

Сопоставление переводов Ю. Хаппалаева с оригиналом демонстрируют, насколько сложно в рамках перевода сохранить содержание стихотворения и одновременно передать его ритмическое и интонационное звучание. Справедливы выводы современных исследователей перевода, что решение этой задачи и заставляет прибегать переводчиков к разного рода трансформациям, которые неизбежно влекут за собой отступления от текста оригинала [5, с. 342]. Соответственно для создания качественного перевода поэтического произведения необходимо использовать различного рода приёмы, обладать чувством стиля и поэтическими способностями, равноценными автору оригинала $[15$, с. 278$]$. Но благодаря нелегкому и кропотливому труду переводчика яркие и выразительные образы Маяковского доступны для восприятия не только на языке оригинала, но и на других языках [17, с. 187].

Оценивая переводы Ю. Хаппалаева с точки зрения ритмико-интонационных особенностей, нужно также отметить, что переводчик еще в 70-е годы прошлого века продемонстрировал новые возможности лакского стиха, показал, что и в его национальной просодии В. Маяковский звучит достаточно приближенно к оригиналу. В те годы его современники, воспитанные на традиционной силлабике, еще не были готовы к новаторским поискам в родной верификации, и переводы Ю. Хаппалаева являлись вершиной экспериментаторства в лакской поэзии. Это был первый опыт в создании 
лакского свободного стиха, способствующий дальнейшему развитию национальной верификационной культуры.

\section{Литература}

1. Алексеева И.С. Введение в переводоведение. - М.: Академия, 2004.

2. Абдуллаев И.Х. Лакское слово и поэт (Лакку махъ ва шяир) // Новолуние (Цубарз). - 1997. - № 4.

3. Абдуллаев А.А. Проблема перевода. - Махачкала, 2007.

4. Арпентьева M.Р. Проблема поэтического перевода // Омский научный вестник. Сер. Общество. История. Современность. - 2018. - № 2.

5. Болгова О.В. Анализ французских переводов стихотворения А.С. Пушкина «Зимнее утро» // Филологические науки. Вопросы теории и практики. - Тамбов: Грамота, 2019. - Т. 12, вып. 5.

6. Гачечиладзе Г. Художественный перевод и литературные взаимосвязи. - М.: Советский писатель, 1980.

7. Заводнова М.В. Особенности перевода стихотворения «Лиличка!» В.В. Маяковского на английский язык // Форум молодежной науки. Гуманитарные науки. 2020. - Вып. 1, № 2 .

8. Идиатуллина Л.Т. Переводы В. Маяковского в отечественных и зарубежных исследованиях // Вестник Казанского государственного университета культуры и искусств. -2010 . - № 3.

9. Идиатуллина Л.Т. Проблема переводной множественности в контексте диалога культур (на примере переводов произведений В. Маяковского на татарский язык) // Мир науки и образования. - 2020. - № 2 (81).

10. Кассиев Э.Ю. Проблемы художественного перевода дагестанской поэзии. Махачкала: Дагкнигоиздат, 1994.

11. Левый И. Искусство перевода. - М.: Прогресс, 1974.

12. Лозинский М.Л. Искусство стихотворного перевода // Перевод - средство взаимного сближения народов. - М.: Прогресс, 1987.

13. Маяковский В. Стихи / пер. на лак. Ю. Хаппалаева // Дружба (Дусшиву). 1975. - № 3.

14. Орагвелидзе Г. Ритм и рифма Маяковского при переводе на французский язык: автореф. дис. ... канд. филол. наук. - Тбилиси, 1964.

15. Павлова A.B., Оботнина В.A. Особенности перевода русской поэзии на английский язык (на материале стихотворения В. Маяковского «Лиличка» // Балтийский гуманитарный журнал. - 2020. - Т. 9, № 1 (30).

16. Файзи А. Школа мастерства // Дружба народов. - 1950. - № 2.

17. Шарафутдинова Л.Р. Анализ перевода поэтических тропов в стихотворении В. Маяковского «Послушайте!» на английский, испанский и турецкие языки // Филологические науки. Вопросы теории и практики. - Тамбов: Грамота, 2017. - № 5 (71), ч. 1.

Поступила в редакциюю 26 мая 2021 г. 
UDC 801.61

DOI: $10.21779 / 2542-0313-2021-36-3-82-94$

\title{
Converting the Rhythm of V. Mayakovsky's Verse in the Translations of Yu. Happalaev
}

\author{
Kh.M. Aminova
}

Dagestan State University; Russia, 367000, Makhachkala, M. Gadzhiev st., 43a; hazinat_63@mail.ru

The article examines the rhythmic and intonational features of the translation of V. Mayakovsky's poems "The Left March" and "To Comrade Nette - a Steamship and a Man" into the Lak language, performed by $\mathrm{Yu}$. Happalaev. Considering the importance of maximum rhythm preservation, the author pays special attention to the transmission of the size, the breakdown of lines, the number of stops in a line, the types of intonation, syntax, and rhyme system. The article provides a comparative analysis of the original and its Lak version based on the methodological setting: all the structural elements of the verse, including the meter, the number of syllables, rhyme, etc. must be translated to the extent that the language of translation, poetic traditions and innovations of literature allow it. The study of the translation of the innovative verse by V.V. Mayakovsky into the Lak language allows us to trace the possibilities of transmitting the tonic, accentuated verse of the Russian poet by means of syllabics. As a result of the conducted research, it can be argued that V. Mayakovsky sounds quite adequate in the Lak language. For Yu. Happalaev's translation was an opportunity not only to display his talent, but also one of the important ways of his development and self-improvement.

Keywords: poetic translation, verse, rhythm, intonation, tonic verse, syllabics, V. Mayakovsky

Received 26 May 2021 